Proceedings

\title{
People-Centred Approach for ICT Tools Supporting Energy Efficient and Healthy Behaviour in Buildings ${ }^{\dagger}$
}

\author{
Ana Tisov 1,*, Dan Podjed 2,*, Simona D'Oca ${ }^{1}$, Jure Vetršek ${ }^{2}$, Eric Willems ${ }^{1}$ and Peter Op't Veld ${ }^{1}$ \\ 1 Huygen Engineers and Consultants, P.O. Box 521, 6200 AM Maastricht, The Netherlands; \\ s.doca@huygen.net (S.D.); e.willems@huygen.net (E.W.); p.optveld@huygen.net (P.O.V.) \\ 2 Institute for Innovation and Development of University of Ljubljana, Kongresni trg 12, SI-1000 Ljubljana, \\ Slovenia; jure.vetrsek@iri.uni-lj.si \\ * Correspondence: a.tisov@huygen.net (A.T.); dan.podjed@iri.uni-lj.si (D.P.); Tel.: +31-880-322-222 (A.T.); \\ +386-31-820-198 (D.P.) \\ + Presented at Sustainable Places 2017 (SP2017) Conference, Middlesbrough, UK, 28-30 June 2017.
}

Published: 15 January 2018

\begin{abstract}
This paper attempts to alter a prevailing assumption that buildings use energy to an understanding that in fact, people use energy. Therefore, to successfully accelerate the transition to a low-carbon society and economy more emphasis should be on motivating people and increasing their awareness leading to an energy efficient building use. In this context, this paper provides insights from the Horizon 2020 MOBISTYLE project. The aim of the MOBISTYLE project is to motivate behavioural change by raising consumer awareness through a provision of attractive personalized information on user's energy use, indoor environment and health, through information and communication technology (ICT) based services. The most relevant motivational factors and key performance indicators (KPIs) for encouraging a more energy conscious and healthy lifestyle were defined by means of a people-centred approach, adopting anthropological inquiries in different settings located in different European Union (EU) countries. Behaviour change is achieved through awareness campaigns, which encourage users to be pro-active about their energy consumption and to simultaneously improve health and well-being.
\end{abstract}

Keywords: energy use; indoor environment; health; behaviour change; people-centred approach

\section{Introduction}

"Buildings represent $40 \%$ of final energy consumption, offering the highest potential for efficiency improvement and savings on energy bills [1]." This is a commonly used explanation of European Union (EU) when arguing the necessity to increase the number of buildings energy retrofits. Consequently, stricter EU regulations are introducing energy labelling and encouraging the use of smart technologies and advanced control strategies.

People often find information from their utility bills, smart meters or energy performance certification (EPC) difficult to understand or credible [2]. Oftentimes, users' behaviours do not match the design intentions as users find building technologies difficult to control since these most often do not comply with their needs and their everyday habits [3-5].

The aim of the MOBISTYLE project is to increase the awareness of the users, change their habits and practices, and show that in fact, their energy usage is correlated to behavioural patterns adopted to achieve comfort at home and work, during their public and private life. The final scope of the MOBISTYLE is to offer attractive services for users and increase their understanding of what buildings and technologies can actually enable and what technology is capable of bringing to support healthy building and lifestyles [6]. 


\section{MOBISTYLE Methodology}

The experiences from practice show that energy efficiency as such is not alone a sufficient motivating factor for all the users [7]. Therefore, a better understanding of the drivers of consumer acceptance and behaviour change in relation to energy efficiency should be developed. In MOBISTYLE, the development of the ICT-based tools is supported by a people-centred approach, involving users as a necessary stakeholder during the design and development processes $[8,9]$.

\subsection{People-Centred Approach in Design and Development of ICT tools}

Through different qualitative inquiries (including focus groups, interviews, and participant observation) people habits were investigated to discover their current practices, use of existing technologies, as well to investigate key factors that would trigger them to change their behaviour. The anthropological approach enables to access 'thick data', as an in-depth understanding of human behaviour, able to penetrate beyond the quantified behaviour of 'big data' collected via technological solutions [10,11]. This understanding defines requirements for developing the ICT tools in order to provide user-friendly and attractive services.

\subsection{Demonstration and Validation of the MOBISTYLE People Centred Approach}

The developed MOBISTYLE people-centred approach was validated for the five demonstration cases in real life operating conditions, in five different locations:

- Social housing apartments at Kildenparken, Aalborg, Denmark;

- University buildings at the University of Ljubljana, Ljubljana, Slovenia;

- Apartments at the Hotel Residence L'Orologio, Turin, Italy;

- Health care centre azM Herstelzorg, Maastricht, The Netherlands;

- Residential houses as part of the Smart City Wroclaw, Wroclaw, Poland.

For each demonstration case, one focus group involving 5-8 people users per case, was carried out. Questions for the participants were in one part unified for all groups and partly adapted to specific cases. In this way, the main topics of the project were discussed with users of the demonstration buildings and the MOBISTYLE common goal was discussed in different settings.

\section{MOBISTYLE Results: People-Centred Recommendations for the Technology Development}

Focus groups, supplemented by participant observation, have proven to be a useful research technique for studying users' habits, motivations, needs and expectations in the MOBISTYLE project since they allowed researchers to study people in a less structured conversation pattern than typically occurs in an ethnographic interview [12].

Findings from the focus groups, supplemented by interviews and participant observation have been instrumental in preparing ten key recommendations (Figure 1) which defined the boundary conditions for the further development of the ICT tools and awareness campaigns, as illustrated in the following sections.

1. Emphasizing smartphones: Smartphones are among the most widespread ICT tools. People in the focus groups preferred the usage of the smartphone as the main platform for communication between the users and the MOBISTYLE service.

2. Self-defined user profiles: Users should have the possibility to create their own user profiles and to set customized personal pro-environmental goals. This can give them a feeling of active participation in defining settings for influencing their own habits. Based on the selection of preference and interests, different parameters can be shown to the users.

3. Customised and location-based advice: By combining measurements from sensors with locationbased services (e.g., weather data), generic and local-specific advice can be prepared according to the local environmental characteristics. In this way, specific energy and health related habits can be supported by taking into account individuals' needs and habits when deployed in the situation of the local environment. 
4. Calm Technology principles: ICT tools should not irritate the user with too frequent unnecessary notifications. Instead, the developers should rely on Calm Technology principles [12], which suggest that the most robust and reliable technologies are those that disappear and weave themselves into the fabric of everyday life until they are indistinguishable from it $[13,14]$.

5. Individual control: Ideally, the user should be able to adjust various parameters influencing his or her indoor comfort through the same ICT tool providing him or her building performance information.

6. Expert advisors: It is recommended to prepare communication material by experts (i.e., researchers) providing advice or explaining tasks which will be encouraged via the ICT tool. Advice should be supported by a trusted reliable source as this can improve people's propensity to behave in a suggested way.

7. Spreading the concept through community leaders and trendsetters: When implementing the technology, the developers should focus on early adopters trendsetters and influencers who are able to motivate others to use the novelty in a community. Furthermore, popular local public figures can help spreading the main message.

8. "Feel the energy" approach: The problem related to energy saving is that energy is often impossible to be felt and cognitively processed. The users are unable to perceive the quantity of energy they are using in their everyday practices. Therefore, energy should be visualised in a clear and understandable way, without using standardised units of measuring energy and power.

9. Public dedication to a goal: The technology used should enable public commitment to a goal, which has to be meaningful and relevant for an individual and a community. Social media or existing local groups in different cases can be used for this purpose.

10. Community size: Buildings with a larger number of inhabitants $(>150)$ witness problems of social bonds breakdown. In such cases, the developers should support establishing new communities and enable people to create new ties for helping each other and exchanging information through the ICT tool.

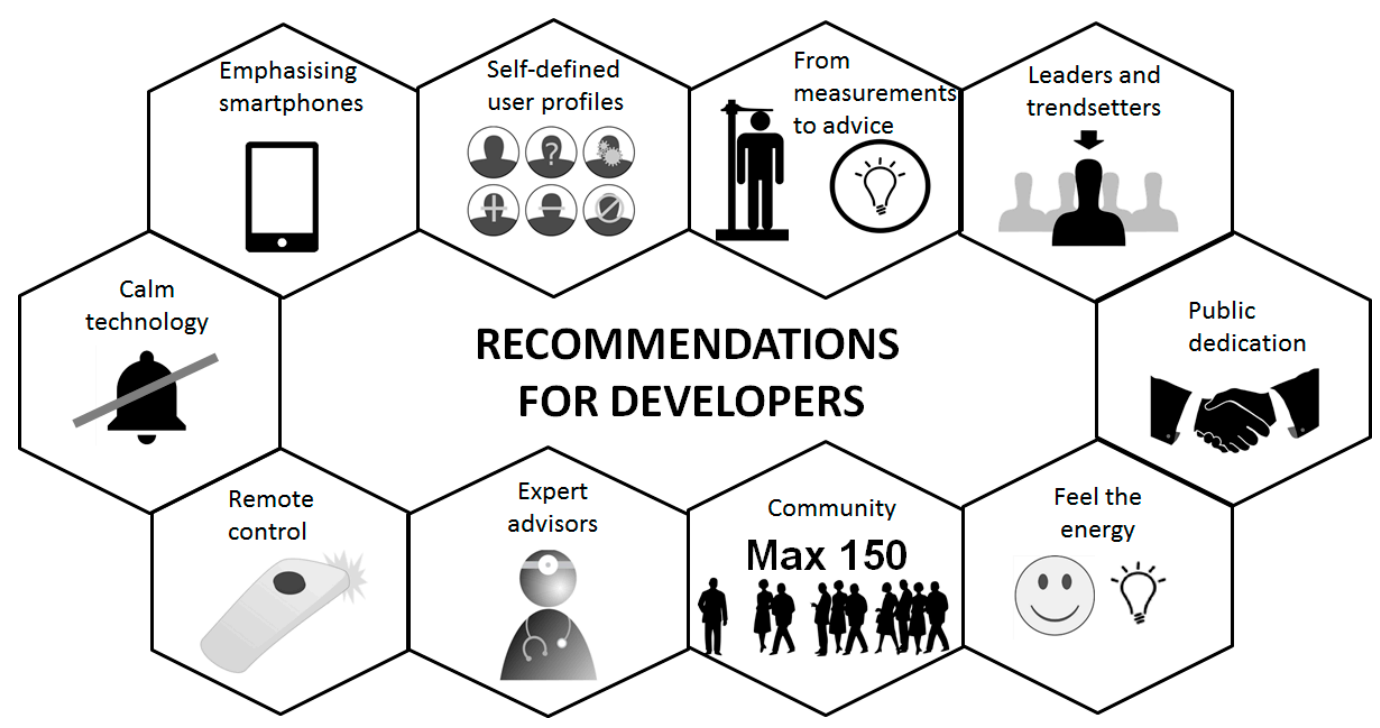

Figure 1. MOBISTYLE recommendations for the ICT developers based on the focus groups findings.

In addition, the research showed that social pressure and community-based support play important roles in changing existing practices and supporting healthy and sustainable lifestyles. Finally, particularities of different demonstration cases should be taken into account when adapting the general ICT tool to different cases and their socio-cultural specifics, people of different age, gender, social and employment status who live and work in different settings, locations, and buildings. Instead of 'one-size-fits-all' approach, the ICT tool should be therefore tailored to different cases and specifics of people, who should have a possibility to change and adapt the tool to individuals needs and attitudes. 


\section{Conclusions}

The aim of the MOBISTYLE approach is to show that improving buildings and building technologies is not enough. In order to achieve ambitious goals of EU on energy savings, a different approach is needed, where users of the buildings are equally important part of the building ecosystem as technologies. Therefore, the emphasis should be on educating users on how to behave in their buildings and how to increase their awareness by combined information on their energy usage, generated IEQ, health, and lifestyle.

Through anthropological observations, it was possible to understand not only how and when people consume energy, but why do they actually do it. This additional layer of personal information opens opportunities to understand and educate users at the individual level, increasing their awareness of how and when their daily habits have an effect on energy consumption. Contributing authors believe that with such an approach a long-term understanding can be stimulated where energy conscious and healthy behaviour becomes a way of life and not only a one-time service, noticed as energy saving at the end of the month.

Finally, it should be emphasised that the people-centred development is an iterative process, which means that the developers should continuously return to users of their products or services to repeatedly ask questions that shed light on how ICT solutions meet their needs and desires.

This range of human-building products is foreseen as a strong support to the implementation of the Energy Performance of Buildings Directive (EPBD) and Energy Efficiency Directive (EED) regulations in the face of achieving 2020 and 2050 energy conservation goals in the European building sector.

Acknowledgments: This project has received funding from the European Union's Horizon 2020 research and innovation programme under the grant agreement No. 723032 (MOBISTYLE). Further information is available online at https://www.mobistyle-project.eu/.

Conflicts of Interest: The authors declare no conflict of interest. The sole responsibility for the content lies with the MOBISTYLE consortium. It does not necessarily reflect the opinion of the European Communities. The European Commission is not responsible for any use that may be made of the information contained therein.

\section{References}

1. European Commission. EASME, Buildings. Available online: https://ec.europa.eu/easme/en/buildings (accessed on 30 May 2017).

2. Nykanen, E.; Piira, K.; Pae, K.; Hildebrandt, D.; Leal, S. D3.4-EEPOS End-Users Collaboration Tool Specification Report; EEPOS: Energy Management and Decision Support Systems for Energy Positive Neighborhoods; Project 7th Framework Programme; Grant Agreement No. 600050; EEPOS: Wiehl, Germany, 2013.

3. Christiansen, E.; Andersen, P.V.K. Digital Living at Home-User Voices about Home Automation. In Proceedings of the Scandinavian Conference on Information Systems (SCIS), Oslo, Norway, 11-147 August 2013; Volume156, pp. 40-52.

4. Gram-Hanssen, K. Understanding change and continuity in residential energy consumption. J. Consum. Culture 2011, 11, 61-78.

5. Gram-Hanssen, K. Residential heat comfort practices: Understanding users. Build. Res. Inf. 2010, 38, 175-186.

6. Krippendorff, K. The Semantic Turn. In A New Foundation for Design; CRC Press: Boca Raton, FL, USA, 2005.

7. Op't Veld, P. MORE-CONNECT: Development and advanced prefabrication of innovative, Multifunctional building envelope elements for modular retrofitting and smart connections. Energy Procedia 2015, 78, 1057-1062.

8. Sanders, E.B.N. Design Research in 2006. Des. Res. Q. 2006, 1, 1-8.

9. Sanders, E.B.N. Co-creation and the New Landscapes of Design. CoDesign 2008, 4, 5-18.

10. Menzies, T.;Williams, L.; Zimmerman, T. Perspective in Data Science for Software Engineering; Morgan Kaufmann: Burlington, MA, USA, 2016; pp. 369-274.

11. Boellstorff, T.; Maurer, B. Data, Now Bigger and Better!; Prickly Paradigm Press: Chicago, IL, USA, 2015.

12. Spradley, P.J. The Ethnographic Interview; Waveland Press: Long Grove, IL, USA, 2016. 
13. Case, A. Calm Technology: Principles and Patterns for Non-Intrusive Design, 1st ed.; O’Reilly Media: Newton, MA, USA, 2015.

14. Weiser, M. The Computer for 21st Century. Available online: https://web.stanford.edu/class/cs240e/ papers/weiser.pdf (accessed on 25 April 2017).

(C) 2018 by the authors; Licensee MDPI, Basel, Switzerland. This article is an open access article distributed under the terms and conditions of the Creative Commons Attribution (CC BY) license (http://creativecommons.org/licenses/by/4.0/). 